\title{
UNA FORMA NO LINEAL DE LEER 'CELESTINA': EL COMPENDIO DE SENTENTIAE COMO MAPA TEXTUAL ${ }^{1}$
}

\author{
Enrique Fernández \\ Princeton University
}

El tema de este estudio es el uso que el anónimo autor del hasta el momento inédito manuscrito Celestina comentada hace de un compendio de sententiae de Cicerón. Este uso es especialmente interesante al ser Celestina comentada de principios de la segunda mitad del XVI, por lo que nos ofrece valiosa información sobre cómo leían la Celestina sus primeros admiradores. ${ }^{2}$ La forma inacabada de borrador de trabajo en que Celestina comentada ha llegado hasta nosotros permite examinar en detalle cómo el compendio ha dirigido la lectura del comentarista que no accede al texto de Celestina de manera lineal, sino que usa las sententiae como hitos de su exploración textual.

En el texto de la versión de 21 actos de Celestina han sido identificadas 332 sententiae cuya importancia para el conjunto de la obra

${ }^{1}$ Una breve versión preliminar de este artículo se leyó en la XXX Conferencia de la Asociación de Hispanistas Canadienses en Calgary, 4 de junio de 1994, en la sesión homenaje a Louise Fothergill-Payne.

${ }^{2}$ Para un estudio detallado del manuscrito y su fecha véase Peter E. Russell, "El primer comentarista crítico de La Celestina: cómo un legalista del siglo XVI interpretaba la Tragicomedia," en Temas de La Celestina y otros estudios del Cid al Quijote (Barcelona: Ariel, 1978): 293-321. Para un estudio parcial de las citas en el manuscrito véase M. Femández Vázquez, "Estudio Filológico del Ms. 17631 de la Biblioteca Nacional de Madrid: Fuentes de La Celestina," Tesis (Madrid: Universidad Complutense, 1984). Cuando citamos el manuscrito es por folio y regularizando sólo puntuación, mayúsculas y separación de palabras; las abreviaturas están resueltas. 
confirma un experimento llevado a cabo por Peter Russell: "He hecho algunas transcripciones del texto rojano omitiendo sententiae, refranes y exempla. ${ }^{3}$ Es curioso ver cómo, así expurgada, la obra asume los rasgos de una comedia humanística de las corrientes" (Russell, "Discordia" 1). Esta abundancia de sententiae se corresponde con el interés que los lectores de los primeros siglos de existencia de la obra mostraban por ellas. Rojas mismo, refiriéndose al trabajo del primer autor, nos dice que, al releerlo, "nuevas sentencias sentía (...) deleitables fontezicas de filosofía (...) por la gran copia de sentencias entrexeridas, que so color de donaire tiene, gran filósofo era [el primer autor] (...)" $(3-4)^{4}$, y en las octavas acrósticas nota que "portava sentencias dos mil" (7).

En el prólogo, una vez más, confirma la importancia de las sententiae contenidas en la obra, que algunos lectores separarán del resto de la obra para utilizar para su provecho (12). Otro testimonio de la atención que los primeros lectores de Celestina prestaban a las sententiae es el tratamiento que de ellas hacen los traductores de la época. Así, las traducciones de Celestina del siglo XVI y XVII, como la traducción al inglés de James Mabbe, de la que luego hablaremos, respetan las sententiae de la obra. Incluso alguna, como la curiosa traducción al latín de Gaspar Von Barth, incluye extensos comentarios a varias sententiae del texto de Celestina.

Para el lector moderno es difícil entender este interés por las sententiae de los lectores antiguos. Consecuentemente, en las puestas en escena de Celestina y en algunas ediciones populares modernas se aligera el texto de muchas de esas sententiae, descartándolas como erudición libresca que lastra la obra. Esta falta de paciencia con las sententiae es un fenómeno relativamente nuevo: en el siglo XIX, al empezar a apreciarse el realismo como uno de los rasgos más encomiables de la Tragicomedia, el interés por las sententiae decae y se las considera el tributo pedante a la erudición renacentista. Además, la gradual desaparición de la Retórica del curriculum escolar a partir del Romanticismo ha tenido como consecuencia la caída en desuso de uno de sus instrumentos de lectura y escritura: el manual o compendio de sententiae y loci communes.

3 "Some rhetoricians distinguished between sententia and other detachable brief rules of life (...); but in practice, maxim, gnome, adage, aphorism, precept, proverb and sententia all became interchangeable terms to identify compressed, memorable statements of the truths of human experience" (Donker, 191).

${ }^{4}$ Las citas del texto de Celestina son por página al segundo tomo de la edición crítica de Miguel Marciales. 
Desde sus días de escuela el lector de la época estaba familiarizado con el uso de compendios. Por ejemplo, los progymnasmata, un ejercicio de composición escolar de antigua tradición, incluían el desarrollo de una chria, una sententia que se desarrolla siguiendo un estricto modelo de ocho partes: alabanza del autor de la sentencia; paráfrasis de la sentencia; pruebas por causa; pruebas por contraste; comparación; ilustración con exempla; cita de auctoritates en apoyo; exhortación como conclusión (France 14). Otro ejercicio común hasta tan tarde como principios del siglo XVIII consistía en el desarrollo de un pasaje de un autor clásico que previamente el profesor había reducido a sus puntos básicos. El alumno tenía que realizar la amplificatio del pasaje con ayuda de un compendio para luego comprobar sus resultados con el original (France 17). La influencia de la formación retórica recibida en la escuela acompañaba al adulto durante toda su vida y su aproximación al fenómeno textual en todos sus aspectos estaba mediatizada por la Retórica.

Si ya en la Edad Media existía un buen número de compendios, los dos siglos que siguen al descubrimiento de la imprenta son los de mayor número de florilegios y compendios publicados (Ong 47). El avance técnico que supuso la invención de la imprenta permitió un sistema de paginación exacta en las ediciones, con lo que se pudo dotar a estos prácticos manuales de índices precisos para la rápida localización de material dentro de su variopinto y abundante contenido. Esta nueva conveniencia es parcialmente responsable del éxito editorial de estos manuales que proliferaron en los siglos XVI y XVII (76 et seq.). No obstante, ya desde el siglo XIII había comenzado una revolución que afectó a la naturaleza del libro. El redescubrimiento en Occidente de la lógica de Aristóteles supone un momento decisivo en la historia del conocimiento humano que empieza a organizarse conforme a una clasificación sistemática del mundo exterior (Parkes 119). Los siglos XVI y XVII serán consecuentemente un momento privilegiado ya que la afición a las tablas y clasificaciones de origen medieval aún pervive, y al mismo tiempo la capacidad técnica recién aportada por la imprenta permite el desarrollo de grandes compendios con una exactitud y una facilidad de manejo impensables hasta el momento.

Como Stanley Fish señala, los modos de escritura de una época están inscritos en sus modos de lectura (171). Deyermond demostró que Rojas utilizó el índice de las edición de Basilea de las obras de Petrarca a modo de compendio para rápidamente encontrar sententiae. También sabemos que Rojas lega en su testamento una copia de la Margarita Poetica, el popular compendio de Albrecht von Eyb probablemente usado 
en la composición de Celestina. ${ }^{5}$ En Seneca and Celestina, Louise Fothergill mostró cómo Rojas se burla en la Tragicomedia de los lectores de compendios de máximas de Séneca que sólo tenían un conocimiento superficial del estoicismo.

De la misma manera en que Rojas empleó compendios al escribir su obra, igualmente los primeros lectores de Celestina usaron de compendios para enriquecer su lectura. Así es el caso de Celestina comentada, el primer comentario extenso de la Tragicomedia que se conoce, aproximadamente de la segunda mitad del siglo XVI. Es un largo manuscrito anónimo de más de 200 folios que se encuentra en la Biblioteca Nacional de Madrid, Ms. 17631. Básicamente se trata de glosas a la Tragicomedia que aportan auctoritates para probar su corrección doctrinal. La forma en que nos ha llegado está pensada para la publicación. No obstante, se puede probar la existencia de varias redacciones previas a la conservada. La redacción conservada pretendía ser la definitiva, pero a última hora el comentarista empezó a incluir más material en los márgenes y entre líneas. El comentarista intentó al principio integrar ese nuevo material con las glosas centrales. Finalmente, la proliferación de adiciones hacen el manuscrito difícil de leer y le convencen de la necesidad de realizar otra copia en limpio. En esta nueva redacción expandiría esas notas y las incluiría en las glosas, pero no sabemos si llegó a hacerla.

En el manuscrito que conservamos, las adiciones posteriores a esa decisión se limitan consecuentemente a meras notas esquemáticas que envían a otras fuentes para aportar más auctoritates o para corregir y ampliar las de la glosa central. En una treintena de ocasiones el comentarista hace referencia en notas marginales muy breves a M.T.Ciceronis sententiae insigniores, un compendio de sententiae de Cicerón y otros autores realizado en Francia en 1547 por Petrus Lagnerius, un legista como Rojas, quien en sus ratos de ocio colecciona pasajes ciceronianos y de otros autores clásicos bajo encabezados temáticos. Su compendio de sententiae y exempla de Cicerón es uno de los muchos que circulaban en la época. Es un libro con casi quinientas páginas que se publica por primera vez en Lyon en 1547. En sucesivas ediciones este compendio se va ampliando con diferentes secciones, como una sección de sententiae de Terencio, otra de Demóstenes y, en ediciones más tardías, incluso de Erasmo, pasando de las 240 páginas de la primera edición a

${ }^{5}$ Para un estudio del uso de la Margarita Poetica por Rojas véase Ivy A. Corfis, "Fernando de Rojas and Albrecht von Eyb's Margarita Poetica," Neophilologus 68 (1984): 206-213. 
las casi 500 de las últimas ediciones. Debió de ser un libro muy popular pues tan sólo en la Biblioteca Nacional de Madrid hay 7 ediciones diferentes, muchas veces encuadernadas con vademecums de la época. Otra prueba de su popularidad es que se siguió editando, y con continuo aumento de páginas, durante casi dos siglos, hasta su última edición en Londres en $1704 .^{6}$

En el compendio de Petrus Lagnerius no existe un índice de páginas a la manera moderna, sino que al final hay un índice alfabético de materias, la única forma de navegar por sus muchas páginas. Este índice de materias tiene entradas para muchos de los capítulos temáticos en que está dividido el compendio, aunque en ocasiones hay capítulos que no tienen entrada en el índice y viceversa, entradas del índice que no corresponden a un capítulo sino a una página donde hay una sententia que puede representar ese tema, aunque esté incluida dentro de un encabezado diferente. Para el lector moderno este tipo de índice no resulta muy informativo ya que, desde su punto de vista, la elección de las palabras incluidas en el índice parece haberse realizado caprichosamente. Sin embargo, este tipo de índice era muy valioso para el lector formado en Retórica, que estaba muy acostumbrado a utilizarlo. Reproducimos la entrada del índice correspondiente a la letra " $E$ " como un buen ejemplo de lo que contiene:

Eligendum ex multis optimum

Eloquentia

Emere malo quam rogare

Error

Eruditio ac scientia

Exemplum et similitudo

Exercitium
208

$35,37,364$

216

392

312

123

281

${ }^{6}$ Aunque no existe ninguna edición impresa en España, en la Biblioteca Nacional de Madrid hay siete ediciones diferentes: Lyon 1547, 1549, 1552, 1560 y 1575; París 1553 y 1575 . Hay igualmente varias ediciones catalogadas en diferentes bibliotecas españolas: tres ejemplares en la Biblioteca Universitaria de Zaragoza (Venecia 1587 [2 ejemplares], Turín 1597), una en la Biblioteca Universitaria de Barcelona (Lyon 1556) y una en la Biblioteca de Palacio (Lyon 1568). Sintomáticamente, la edición que usa el comentarista, la de París 1575 , es la edición de la que se conservan más ejemplares en España: un ejemplar en la Biblioteca Pública de Burgos y otro en la Biblioteca Pública de Toledo. Estas dos, sumadas a la de la Biblioteca Nacional de Madrid, contabilizan un total de tres ejemplares de la misma edición. En total hemos podido contabilizar un total de catorce ejemplares registrados en bibliotecas españolas. Esto es buena prueba de la popularidad y difusión del libro entre los lectores españoles. 
Exilium

Expetendorum tria genera
127

81

El autor de Celestina comentada en sus notas marginales o interlineales se vale de este índice para indicar sus referencias al compendio. Así, en vez de indicar la página del compendio a la que quiere remitir, escribe en castellano o en latín al margen de un pasaje de Celestina "Véase la palabra (...)," refiriéndose a una de las entradas del índice que envía a una o más páginas del compendio. Un buen ejemplo del uso de este índice por el comentarista es una de las entradas del índice que más utiliza. En varias ocasiones el comentarista se limita a anotar al margen del texto de Celestina, "ver 'hominem' en Lagnerio." Se está refiriendo al capítulo del compendio "hominem esse calamitosum," que en el índice aparece escuetamente listado como "hominem." Dentro de un marco cristiano-estoico es evidente lo que va a aparecer en este capítulo: auctoritates sobre la frágil y penosa condición del ser humano. El comentarista envía a este capítulo para comentar las siguientes sententiae de la Tragicomedia:

Acto 4, Celestina convenciendo a Melibea: "Que no se puede dezir nacido el que para sí solo nació" (86).

También Celestina en el acto 4: "La vegez no es sino mesón de enfermedades" (80).

Acto 6, Calisto a mozos: "Pues no ay bien complido en esta penosa vida" (119).

Por ejemplo, para las palabras de Calisto del acto 6 que acabamos de citar, el comentarista escribe la siguiente nota marginal: "Y Séneca: 'Ea est humanarum rerum natura ut nihil sit omni ex parte beatum'. Pedro Lagnerio lo refiere: 'Variorum authorum,' cap. 'Hominem esse calamitosum'" (fol. 114v)?

Las palabras de Celestina a Pármeno cuando ésta lo quiere ganar para su causa al final del acto 1 diciéndole: "De los hombres es errar y bestial es la porfía," aparecen comentadas en la glosa central de Celestina comentada con alusiones a numerosos pasajes de la Biblia y de San Jerónimo. En la anotación al margen fruto de la última revisión se remite a dos capítulos del compendio titulados respectivamente "Exemplum" y "Populus." En estos dos capítulos hay varias sententiae que ejemplifican

${ }^{7}$ No es de Séneca ni de Séneca rhetor. Probablemente es de uno de los muchos tratados apócrifos que circulaban bajo el nombre de Séneca, como los Proverbia Senecae o el Liber de moribus (Blüher 71). 
un punto de la moral estoico-cristiana: el sabio debe evitar seguir a la plebe en sus decisiones pues ésta suele equivocarse.

Como es de esperar, el uso del compendio es más frecuente para los pasajes de la Tragicomedia en los que más abundan las sententiae. Así, la conversación entre Celestina y Melibea en el acto 4 presenta varias notas marginales que refieren al compendio. Opuestamente, es muy interesante notar la ausencia absoluta de anotaciones que remitan al compendio en los actos 15-19 inclusive, los actos añadidos que diferencian la Comedia de la Tragicomedia. Aunque hay otros actos en los que no se usa en absoluto el compendio $(5,10,11,13)$, esta secuencia de actos contiguos sin usar el compendio no ocurre con ninguno de los otros actos. También es interesante señalar que las palabras de Celestina son las que más veces se comentan mediante el compendio, seguidas en frecuencia por las de Calisto, Pármeno y Sempronio. Hay por tanto y como es lógico una relación directa entre el uso de sententiae en la Tragicomedia y el uso del compendio por el comentarista.

Es también interesante notar qué tipo de material busca el comentarista en el compendio. De manera semejante a como hace en las glosas del cuerpo central de Celestina comentada, en las notas marginales el comentarista no está interesado en el estudio de las fuentes tal y como las entendemos hoy, aunque no por eso deja de señalarlo cuando el parecido entre Celestina y una auctoritas es muy grande. Principalmente el compendio le sirve al comentarista para un enriquecimiento del texto de Celestina mediante la aportación de una sentencia nueva que complementa la que aparece en la Tragicomedia. Por ejemplo, en el acto 4, Melibea recrimina a Celestina por su misión como embajadora de Calisto diciéndole: "Que el más empecible miembro del mal ombre o muger es la lengua" (87). En la glosa central el comentarista había señalado el pasaje de Petrarca del que procede esta sententia. La anotación al margen aporta una nueva sententia que refiere al capítulo "taciturnitatis" del compendio. La anotación marginal dice: "Y de aquí se dize: 'Mors et vita in manibus linguae'. Lagnerio, 'Variorum authorum', cap. 'Taciturnitatis'" (fol. 92v). La relación entre la auctoritas aducida y la sententia glosada no es la de fuente. Gracias al compendio el comentarista logra aportar una nueva variante, aun más dramática y adecuada a los riesgos que corre Celestina en su misión de embajadora de Calisto si Melibea la denuncia ante la justicia por alcahuetería, así como del peligro de muerte en que se halla la honra de Melibea si accede a las palabras de Celestina.

En otras ocasiones lo que el comentarista ha hecho es buscar una auctoritas latina para confirmar la validez de un refrán popular castellano. 
Así, en el acto 2 Pármeno, reprendido por Calisto a pesar del buen consejo que éste le acaba de dar, dice: "Mal me quieren mis comadres" (61). Se trata del comienzo de un refrán: "Mal me quieren mis comadres porque les digo las verdades, bien me quieren mis vecinas porque les digo las mentiras." El comentarista escribe al margen de este pasaje: "Tulius: 'Hoc tempore obsequium amicos, veritas odium parit.' Petrus Lagnerius 'Variorum authorum' cap. 'Corrupti mores' pagina 155" (fol. $67 \mathrm{r})^{8}$

Las alabanzas que Celestina dedica al vino en el banquete con sus pupilas, Pármeno y Sempronio, "pues de noche en invierno no hay tal escalentador de cama" (159), son anotadas al margen por el comentarista: "Vide Petrum Lagnerium 'Variorum authorum', cap. 'Sobrietatis', pagina 309" (fol. 137v). En ese caso no es una sententia lo que se está comentando sino que se usa el compendio para aclarar un pasaje de costumbres. El capítulo "Sobrietatis" al que envía el comentarista cubre casi la página 309 del compendio con citas de diversos autores contra el uso inmoderado del vino. De esta manera el comentarista puede desautorizar, o al menos matizar, las excesivas alabanzas al vino de la vieja "alcoholada" Celestina.

El cuadro en las páginas $40-41$ da una buena idea del tipo de auctoritates que el comentarista encuentra en los diferentes capítulos del compendio.

En numerosas ocasiones el comentarista no copia en su nota marginal una auctoritas concreta del compendio sino que sus referencias son más generales. Así, comentando las lamentaciones de Celestina en el acto 3 por la muerte de Claudina, compañera de prostitución y brujería: "Oh muerte, muerte, a cuántos privas de agradable compañía" (66), el comentarista escribe al margen en latín: "Vide aliquid in mortem per Petrum Lagnerium in cap. 'De morte,' pagina 70" (fol. 70v). Ese "vide aliquid in mortem" refleja muy bien su actitud hacia el compendio. El comentarista no se limita a una simple identificación de pasajes similares, sino que utiliza el compendio como repertorio que le permite encontrar temas que comentar. El material en el capítulo "De morte," que empieza en la página 70 del compendio y se extiende hasta la 73, es muy variado, con abundancia de citas que pueden servirle como auctoritates para comentar y ampliar las palabras de Celestina sobre cómo la muerte arrebata los placeres.

\footnotetext{
${ }^{8}$ Laelius de amicitia 89. "Hoc tempore" no aparece en Cicerón.
} 
Medio siglo más tarde en Inglaterra tenemos otro interesante ejemplo de esta forma de leer Celestina asociando los temas con los encabezados de las secciones bien conocidas de los topoi. El traductor al inglés de Celestina, James Mabbe, en el manuscrito Alnwick que precede a la edición de su traducción, hace breves anotaciones marginales que sorprenden en su brevedad por el parecido con las anotaciones al margen de Celestina comentada que refieren al compendio de Petrus Lagnerius. Así, al margen de las palabras de Sempronio en el acto 3, "que la costumbre luenga amansa los dolores, afloxa y deshaze los deleites, desmengua las maravillas" (65), James Mabbe se limita a anotar la palabra inglesa "custome", tras haber traducido sin ningún problema el pasaje (Mabbe, 160). Curiosamente el autor de Celestina comentada en su nota marginal para el mismo pasaje aduce una sententia de Cicerón ("los que muchas veces han sufrido muchas cosas con más facilidad sufren lo que les acontece" [fol. 69v]), que remite al capítulo "consuetudo" del compendio de Lagnerius. Unas veces en latín y otras en inglés, Mabbe anota al margen de su traducción del texto de la Tragicolnedia frases cortas o palabras como "Divitiae, bona fortuna" (127), "Amicitia inter pares" (145), "Incomodities of old age"(169), "Friends" (170) y otros términos que a simple vista parecen no aportar nada, pero en su brevedad son referencias a dónde encontrar más material. 


\begin{tabular}{||l|c|l||}
\hline \multicolumn{1}{|c|}{ Pasaje de Celestina } & \multicolumn{1}{|c|}{$\begin{array}{c}\text { Cap. del } \\
\text { compendio }\end{array}$} & \multicolumn{1}{|c||}{ Auctoritas aportada } \\
\hline $\begin{array}{l}\text { Celestina, I, 52: De los ombres } \\
\text { es errar y bestial es la porfía }\end{array}$ & $\begin{array}{c}\text { Ignoscitur quibus } \\
\text { facile }\end{array}$ & $\begin{array}{l}\text { Humanum est errare sed ferinum } \\
\text { perseverare in errore est (del propio } \\
\text { Lagnerius, 54v) }\end{array}$ \\
\hline $\begin{array}{l}\text { Calisto, II, 60: ¿No sabes que } \\
\text { el primer escalón de la locura } \\
\text { es creerse ser ciente? }\end{array}$ & Prudentia & $\begin{array}{l}\text { Primus ad sapientiam gradus se } \\
\text { ipsum nosse, quod ut omnium } \\
\text { difficillimum est, ita longe } \\
\text { utilissimum (Cicerón, 65v) }\end{array}$ \\
\hline $\begin{array}{l}\text { Pármeno, II, 61: Mal me } \\
\text { quieren mis comadres etc. }\end{array}$ & Corrupti mores & $\begin{array}{l}\text { Hoc tempore obsequium amicos, } \\
\text { veritas odium parit (Cicerón, 67r) }\end{array}$ \\
\hline $\begin{array}{l}\text { Sempronio, III, 65: Que la } \\
\text { costumbre luenga amansa los } \\
\text { dolores, afloxa y deshaze los } \\
\text { deleites, desmengua las } \\
\text { maravillas }\end{array}$ & Consuetudo & $\begin{array}{l}\text { Qui multa sunt saepe perpessi facilius } \\
\text { ferunt quicquid accidit (Cicerón, 69v) }\end{array}$ \\
\hline $\begin{array}{l}\text { Celestina, IV, 75: Porque } \\
\text { aquellas cosas que bien no } \\
\text { son pensadas, aunque algunas } \\
\text { vezes ayan buen fin, } \\
\begin{array}{l}\text { comúnmente crían } \\
\text { desvariados efetos }\end{array}\end{array}$ & Exercitii seu \\
\hline $\begin{array}{l}\text { laboris } \\
\text { mía fe, la vegez no es sino } \\
\text { mesón de enfermedades }\end{array}$ & $\begin{array}{l}\text { Vigilando, agendo, bene consulendo, } \\
\text { prospere omnia cedunt (Salustio, 76v) }\end{array}$ \\
\hline
\end{tabular}




\begin{tabular}{||l|c|l||}
\hline $\begin{array}{l}\text { Celestina, IV, 81: Las riquezas } \\
\text { no hazen rico, mas ocupado }\end{array}$ & $\begin{array}{c}\text { Paupertatis ac } \\
\text { divitiarum }\end{array}$ & $\begin{array}{l}\text { Opes sunt sarcinae mentis (Cicerón, } \\
83 \mathrm{r} \text { ) }\end{array}$ \\
\hline $\begin{array}{l}\text { Melibea, IV, 87: Que el más } \\
\text { empecible miembro del mal } \\
\text { ombre o muger es la lengua }\end{array}$ & Taciturnita tis & $\begin{array}{l}\text { Mors et vita in manibus linguae } \\
\text { (Heliodoro, 92v) }\end{array}$ \\
\hline $\begin{array}{l}\text { Calisto, VI 119: Pero, pues no } \\
\text { ay bien complido en esta } \\
\text { penosa vida }\end{array}$ & $\begin{array}{l}\text { Hominem esse } \\
\text { calamitosum }\end{array}$ & $\begin{array}{l}\text { Ea est humanarum rerum natura ut } \\
\text { nihil sit omni ex parte beatum } \\
\text { (Séneca, 114v) }\end{array}$ \\
\hline $\begin{array}{l}\text { Celestina, VII, 124: El cierto } \\
\text { amigo en la cosa incierta se } \\
\text { conoce }\end{array}$ & Amicitiae & $\begin{array}{l}\text { Is amicus est qui in re dubia re juvat } \\
\text { ubi re est opus (Plauto, 117r) }\end{array}$ \\
\hline $\begin{array}{l}\text { Pármeno, VIII, 148: Nunca } \\
\text { venir plazer sin contraria } \\
\text { çoçobra en esta triste vida }\end{array}$ & Voluptatis & \begin{tabular}{l} 
Miscentur tristia letis (Ovidio, 132v) \\
\hline $\begin{array}{l}\text { Celestina, IX, 159: Pues de } \\
\text { noche en invierno no ay tal } \\
\text { escallentador de cama } \\
\text { [refiriéndose al vino] }\end{array}$
\end{tabular} Sobrietatis \\
\hline $\begin{array}{l}\text { Calisto, XIV, 234: Mas cuando } \\
\text { el vil está rico, ni tiene } \\
\text { pariente ni amigo }\end{array}$ & $\begin{array}{l}\text { Domini ac } \\
\text { servitutis }\end{array}$ & $\begin{array}{l}\text { Homini cicuta est vinum (Plinio). } \\
\text { Vino forma perit, vino corrumpitur } \\
\text { etas. Vinum memoriae mors } \\
\text { (Propercio, 137v) }\end{array}$ \\
\hline \hline
\end{tabular}


En el caso de Celestina comentada podemos incluso reconstruir el orden en que el comentarista ha realizado algunas de las anotaciones marginales que envían al compendio. Muchos de los capítulos del compendio de Lagnerius aducidos para comentar pasajes de diferentes actos de la Tragicomedia están en páginas contiguas del compendio, algo que no se puede atribuir a una coincidencia en un volumen de casi 500 páginas. Se ha producido por tanto un movimiento de lectura inverso, del compendio a la tragicomedia, ya que es el orden del material en el compendio lo que produce el orden del comentario - relectura- de Celestina. En el siguiente cuadro se incluyen ejemplos de cómo los capítulos aducidos del compendio se agrupan en series que se hallan en páginas adyacentes:

\begin{tabular}{|c|c|c|c|}
\hline \multicolumn{2}{|r|}{ CELESTINA } & \multicolumn{2}{|r|}{ COMPENDIO } \\
\hline $\begin{array}{l}\text { A } \\
\text { ct }\end{array}$ & Pasajes comentado & Pág & Capit. aducido \\
\hline 2 & Mal me quieren mis comadres (61) & 155 & Corrupti mores \\
\hline 3 & $\begin{array}{l}\text { Que la costumbre luenga amansa los dolores } \\
\text { etc. (65) }\end{array}$ & 156 & Consuetudo \\
\hline $\begin{array}{l}1 \\
2\end{array}$ & El ombre apercebido, medio combatido (197) & 158 & Repentina graviora \\
\hline 4 & $\begin{array}{l}\text { Que no se puede dezir nacido el que para sí } \\
\text { solo nació (86) }\end{array}$ & 159 & $\begin{array}{l}\text { Hominem esse } \\
\text { calamitosum }\end{array}$ \\
\hline 4 & Las riquezas no hazen rico, mas ocupado (81) & 294 & $\begin{array}{l}\text { Paupertatis ac } \\
\text { divitiarum }\end{array}$ \\
\hline $\begin{array}{l}1 \\
4\end{array}$ & ¡O breve deleite mundano! (233) & 295 & Exercitii seu laboris \\
\hline 8 & $\begin{array}{l}\text { Nunca venir plazer sin contraria çoçobra en esta } \\
\text { triste vida (148) }\end{array}$ & 297 & Voluptatis \\
\hline 9 & $\begin{array}{l}\text { Pues de noche en invierno no hay tal } \\
\text { escalentador de cama [como el vino] (159) }\end{array}$ & 309 & Sobrietatis \\
\hline 4 & $\begin{array}{l}\text { Que el más empecible miembro del mal ombre } \\
\text { o muger es la lengua (87) }\end{array}$ & 310 & Taciturnitatis \\
\hline
\end{tabular}


Examinemos un ejemplo de este tipo. Las palabras de Celestina en su primera visita a Melibea en el acto 4 hablando de la riqueza, "aquel es rico que está bien con Dios" (81), dan lugar a dos notas marginales que remiten al compendio. Además de la glosa central con varias referencias a Séneca y Petrarca entre otros, en esta nueva nota marginal se dice: "Vide Petrum Lagnerium 'Variorum authorum', cap. 173, incipit 'dives"' (fol. 83r). Con este "incipit" se refiere a la serie de capitulos que a partir de ese punto aparecen en el compendio que son: "Dives" (cap. 173), "Pauper" (174), "Dives vix bonus" (175), "Pecuniae et divitiae" (176), "Avaritia" (177) y "Multi pauperes" (178). El índice del compendio lo envió a este filón de citas por la entrada "dives" que mandan directamente a la página donde se encuentra el capítulo 173. Al margen de la nota anterior, escrito claramente más tarde por su situación en el folio, escribe el comentarista: "Vide Petrum Lagnerium cap. 'Paupertatis' pag. 294" (fol 83r). El capítulo "Paupertatis" no se puede encontrar en el índice del compendio por no aparecer listado.

Curiosamente, la página citada por el comentarista, la 294, no es el comienzo del capítulo, que está dos páginas antes realmente, sino que es la página contigua al capítulo "Exercitii seu laboris et ignaviae," página 295, que el comentarista había citado en anotación marginal al pasaje de Celestina "Porque aquellas cosas que bien no son pensadas, aunque algunas vezes ayan buen fin, comúnmente crían desvariados efetos" (75). Probablemente durante su trabajo con el capítulo "Exercitii seu laboris et ignaviae" llamó la atención del comentarista alguna de las frases de la página contigua, quizá "Qui suị contentus est, ditissimus est" (Cicerón)", u otra de las varias allí citadas. Esto explica la existencia de dos anotaciones en el mismo folio y para el mismo pasaje: una procede de la búsqueda por el índice, lo que explica su generalidad ("incipit dives") y la otra es fruto del azar, por ello se cita la página exacta y luego el capítulo por si pudiera generar alguna otra cita pertinente. En síntesis, cuando el comentarista estaba glosando un pasaje de la Celestina usando un capítulo del compendio y vio en la página contigua del compendio una serie de auctoritates, estas le trajeron a la memoria otro pasaje de Celestina. Entonces en su relectura-comentario dio un salto a otro punto del texto de la Tragicomedia dejando que el orden del compendio le guiase a modo de mapa para acceder al territorio textual de la Tragicomedia de manera no lineal. Las sententiae de Celestina se convierten así en hitos de una geografía supratextual que no se corresponde con la simple fábula de la historia.

${ }^{9}$ Realmente no es de Cicerón. Por lo abreviado de la frase parece sacada a su vez de algún florilegio medieval que la referiría a Cicerón. 
Es interesante confrontar esta forma de "re-leer" Celestina a través de un compendio con el moderno concepto de intertexto, definido por Rifaterre como "l'ensemble des textes que l'on retrouve dans sa mémoire [del lector] à la lecture d'un passage donné" (citado por Oliver 8). Para un lector de los primeros tiempos de Celestina y con formación retórica, la intertextualidad era algo mucho más complejo que la capacidad de recordar pasajes análogos, ya que incluía también la serie de mecanismos de conexión adquiridos durante su formación retórica que le permitían la localización de auctoritates relacionadas con el pasaje leído. El "informed reader" del siglo XVI no se enfrentaba a las sententiae de la Tragicomedia con sólo los recursos de su memoria para reconocerlas e interpretarlas. Su formación retórica le había adiestrado en el uso de los compendios, en los que cada sententia estaba encuadrada dentro de un marco general de referencia. Los mecanismos de localización dentro de ese marco de referencia son específicos y pertenecen a lo que Fish denomina sistema de inteligibilidad, el conjunto de estrategias de interpretación compartidas por una comunidad interpretativa, que son "publicly available," como es el caso de los compendios (332).

Thomas Greene indica que la relación del texto medieval con sus modelos anteriores es una relación metonímica, mientras que la relación del texto renacentista con los modelos anteriores es una relación metafórica. El texto medieval está en continua evolución al añadírsele nuevos textos contiguos que lo completan de manera metonímica. El texto renacentista busca nuevos parecidos que hasta entonces no habían sido apercibidos, siendo el parecido la base de la metáfora (86). Los compendios se prestan tanto a una utilización metonímica como metafórica, lo que explica su exitosa supervivencia desde el siglo XIII hasta el XVIII. La disposición en la página de las auctoritates induce a un uso de materiales contiguos sobre el mismo tema por el mero hecho de su situación.

Sin embargo esa misma ubicación relativiza las auctoritates, pues la misma cita aparece en diferentes capítulos para ejemplificar diferentes conceptos. Además, un capítulo dedicado al tema de las relaciones del criado y el señor comparte página con un capítulo dedicado al amor y sus excesos. Las posibilidades de notar semejanzas se ven multiplicadas por este "estar al lado de" que produce el compendio. El índice, con el factor de anarquía lógica introducida por la ordenación alfabética, produce temas que no están conectados en una clasificación lógicoescolástica aparezcan como contiguos. El escritor-lector, que ha sido entrenado en el manejo de esos compendios de una manera unívoca y al servicio de un texto central, descubre la infinidad de posibilidades que 
se abren al aparecer ante sí los miembros mutilados de un sistema que se pretendía único e indivisible.

En la "Carta del autor a un su amigo," Rojas escribe refiriéndose al primer acto: "[L]eílo tres o cuatro vezes, y tantas cuantas más lo leía, tanta más necessidad se me ponía de releerlo y tanto más me agradava y en su processo nuevas sentencias sentía" (3). Hay que preguntarse si esas relecturas de Rojas obedecerían al tipo de lectura del autor de Celestina comentada, y si "el proceso," como dice Rojas, se refiere más a una labor de trabajo con un compendio que a la mera lectura lineal a la búsqueda de sententiae. La continuidad y semejanza de las sententiae en los restantes 20 actos hace pensar en una amplia labor con compendios por parte de Rojas para ampliar las ideas originales contenidas en el primer acto. Cuando nos dice que "toda palabra del ombre ciente está preñada" (9), esta preñez requiere del uso de la Retórica a través del compendio como comadrona que ayude en el parto. No nos debe por tanto sorprender que la lectura de las sententiae dos mil fuera un ejercicio tan apasionante ya que conllevaba mucho más que una simple lectura pasiva.

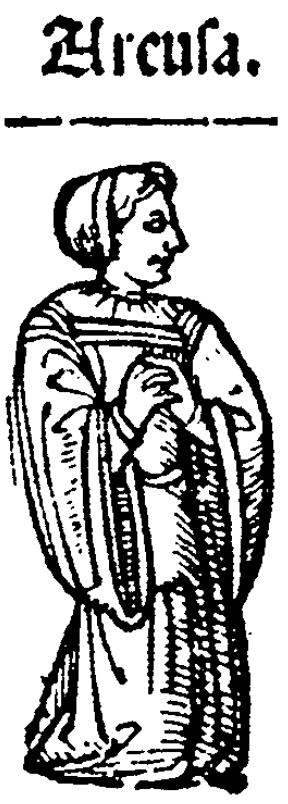

De la ed. de Salamanca 1529. 


\section{Obras citadas}

BARTH, Gaspar Von, tr. Pornoboscodidascalus Latinus. Frankfurt, 1624. BLÜHER, Karl Alfred. Séneca en Espafla: Investigación sobre la recepción de Séneca en Espafta desde el siglo XIII hasta el siglo XVII. Trad. Juan Conde. Madrid: Gredos, 1983.

Celestina comentada. Ms. 17631. Biblioteca Nacional de Madrid. Madrid.

CORFIS, Ivy A. "Fernando de Rojas and Albrecht von Eyb's Margarita Poetica." Neophilologus 68 (1984): 206-213.

DEYERMOND, A.D. The Petrarchan Sources of La Celestina. 1961. Westport, Connecticut: Greenwood Press, 1975.

DONKER, Marjorie, y George M. Muldrow. Dictionary of LiteraryRhetorical Conventions of the English Renaissance. Westport: Greenwood Press, 1982.

FERNANDEZ-VAZQUEZ, Modesto. Estudio Filológico del Ms. 17631 de la Biblioteca Nacional de Madrid. Tesis. Universidad Complutense, 1983.

FISH, Stanley. Is There a Text in this Class?: The Authority of Interpretive Communities. Cambridge: Harvard UP, 1980.

FOTHERGILL-PAYNE, Louise. Seneca and Celestina. Cambridge: Cambridge UP, 1988.

FRANCE, Peter. Rhetoric and Truth in France: Descartes to Diderot. Oxford: Clarendon Press, 1972.

GREENE, Thomas $M$. The Light in Troy: Imitation and Discovery in Renaissance Theory. New Haven: Yale UP, 1982.

LAGNERIUS, Petrus. M.T. Ciceronis sententiae insigniores, apophtegmata, parabolae seu similia, atque eiusdem aliquot piae sententiae. Lugduni, 1575.

MABBE, James, tr. Celestine or the Tragick-Comedie of Calisto and Melibea. Transcription of the Alnwick manuscript by Guadalupe Martinez Lacalle. London: Tamesis Books, 1972.

MARCIALES, Miguel, ed. Celestina: Tragicomedia de Calisto y Melibea. Illinois Medieval Monographs 1. Al cuidado de Brian Dutton y Joseph T. Snow. 2 vols. University of Illinois Press: Urbana, 1985.

OLIVER, Andrew. "Introducción." Texte: Revue de Critique et de Theorie Litéraire 2 (1983) Número especial: L'intertextualité: intertexte, autotexte, intratexte: 5-11

ONG, Walter E. Rhetoric, Romance and Technology: Studies in the Interaction of Expression and Culture. Ithaca: Cornell UP, 1971.

PARKES, Malcolm Beckwith. "The Influence of the Concepts of Ordinatio and Compilatio on the Development of the Book." Medieval Learning and Literature: Essays Presented to Richard William Hunt. 
Ed. J.J.G. Alexander y M.T. Gibson. Oxford: Clarendon Press, 1976. 115-141.

RUSSELL, Peter. "Discordia universal: La Celestina como 'floresta de philosophos'." Insula 497 (abril 1988): 1+.

"El primer comentario crítico de La Celestina: cómo un legista del siglo XVI interpretaba la Tragicomedia." Traduc. Alberto Corazón. Temas de La Celestina. Letras e Ideas. Barcelona: Ariel, 1978. 293-321. Traducción española de "The Celestina comentada." Medieval Hispanic Studies Presented to Rita Hamilton. Ed. A.D. Deyermond. Londres: Tamesis, 1976. 175-193.

\section{Año.

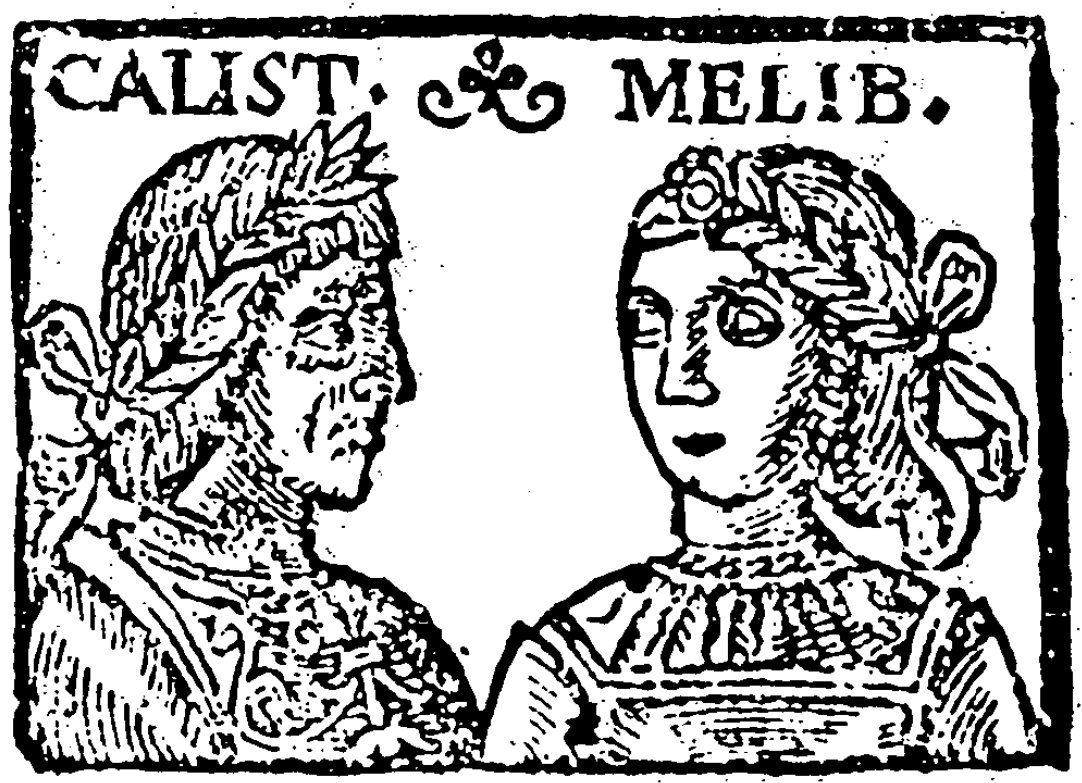

Estella: Adrian de Anvers, 1560. 


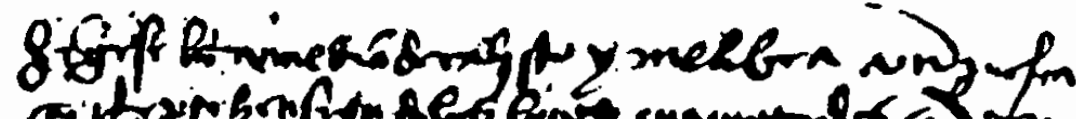

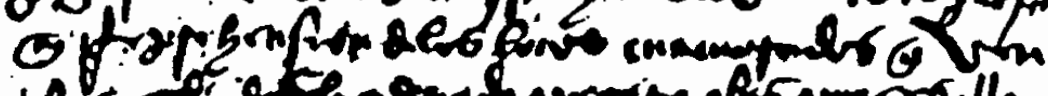

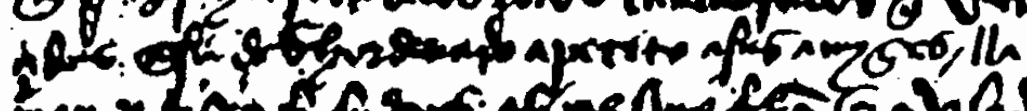

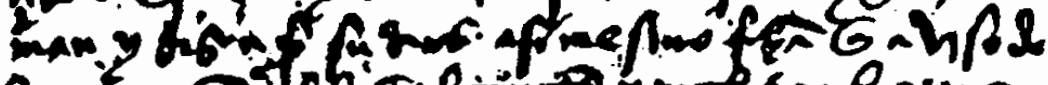

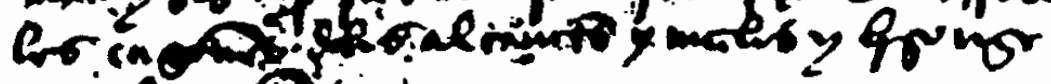
propings is

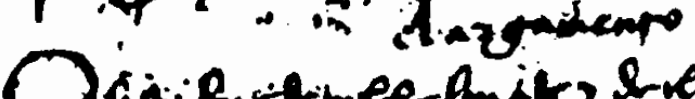

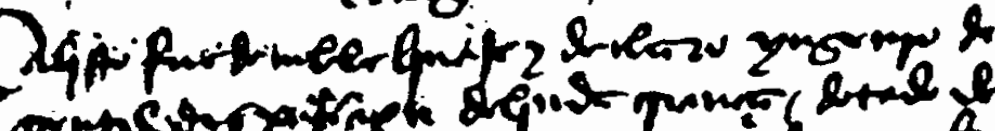

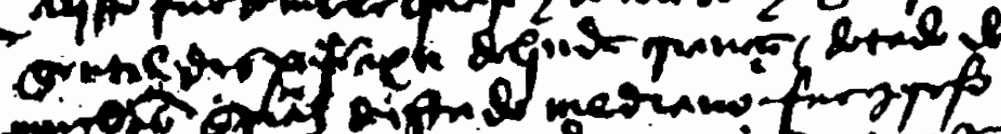

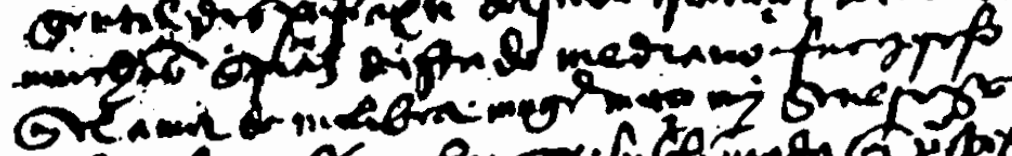

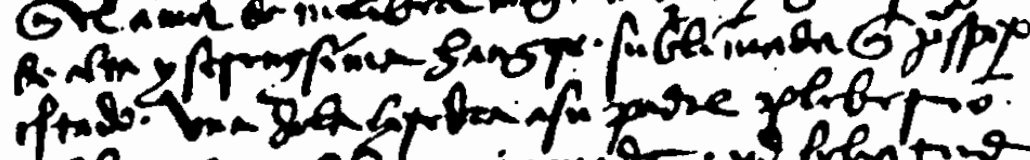

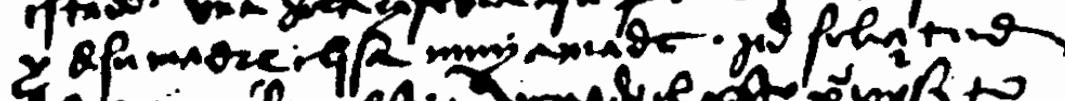

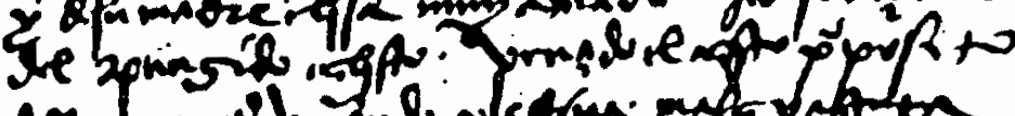

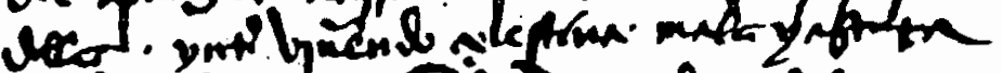

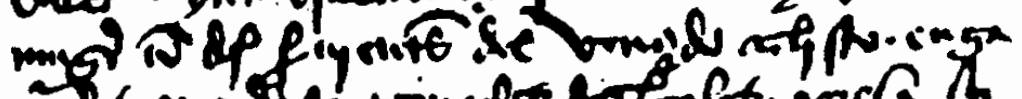

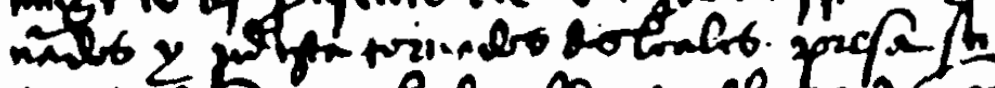

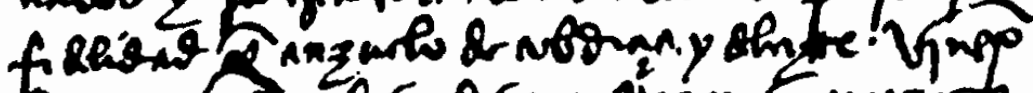

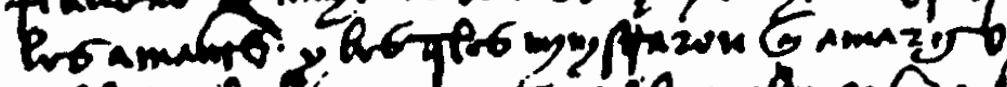

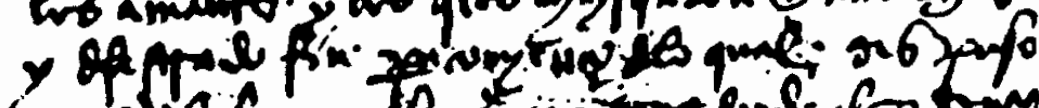

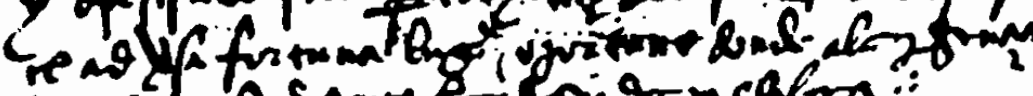

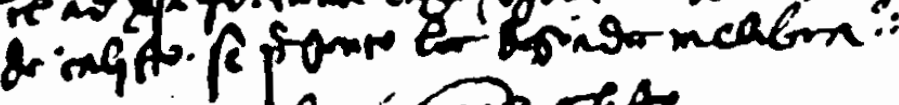

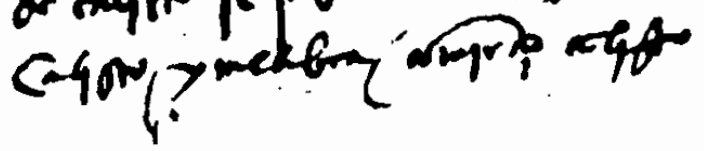

Primera página del Acto I de La Celestina, manuscrito 1520, Biblioteca del Palacio Real, Madrid 